\title{
Sex/Gender Psychological Differences in the Adult Diabetic Patient and How a Child's Response to Chronic Disease Varies with Age and Can Be Influenced by Technology
}

\author{
Maria Antonietta Taras ${ }^{1, *}$ and Alessandra Pellegrini ${ }^{2,+}$ \\ 1 Diabetes and Metabolic Diseases Unit, 07026 Olbia, Italy \\ 2 Freelance Psychologist and Psychotherapist, 90121 Palermo, Italy; alinacpellegrini@gmail.com \\ * Correspondence: anto.ta@inwind.it \\ + On behalf of the SIMDO working group of Psycology.
}

check for

updates

Citation: Taras, M.A.; Pellegrini, A. Sex/Gender Psychological

Differences in the Adult Diabetic

Patient and How a Child's Response to Chronic Disease Varies with Age and Can Be Influenced by Technology. Diabetology 2021, 2, 215-225.

https://doi.org/10.3390/

diabetology2040019

Academic Editor: Giancarlo Tonolo

Received: 2 September 2021

Accepted: 11 October 2021

Published: 1 November 2021

Publisher's Note: MDPI stays neutral with regard to jurisdictional claims in published maps and institutional affiliations.

Copyright: (C) 2021 by the authors. Licensee MDPI, Basel, Switzerland. This article is an open access article distributed under the terms and conditions of the Creative Commons Attribution (CC BY) license (https:/ / creativecommons.org/licenses/by/ $4.0 /)$.

\begin{abstract}
Chronic diseases have a negative impact on quality of life and perceived well-being. Depression tends to be more frequent in people with chronic diseases than the general population, and, for example, in diabetes, it has an incidence of two to three times higher and often remains underdiagnosed. The inability to control and predict the course of the disease exposes chronic patients to mood fluctuations which are often difficult to manage, also in virtue of the fact that in any chronic pathology a stabilization aimed at attenuating the symptoms or slowing the course is pursued, but it cannot tend to achieve complete healing. This fact of incurability for many subjects means the loss of control over their own body, in which the social and family role is also perceived as compromised and the experienced distress can result in the appearance of underlying disorders, both psychological or psychiatric. In this area, there is currently a great deal of focus on sex/gender differences. The aim of this article is to highlight these differences with regard to the emotional aspects that most affect the management of diabetic pathology. In this paper, we will underline a particularly underestimated eating disorder: diabulimia, then that the perception of itself is not only related to the sex assigned at birth, but also to the gender that is acquired during life, and we will also analyze the three phases related to the acquisition of gender identity during the evolutionary period. Finally, we will talk about the use of technology in diabetic patients (insulin pumps, continuous glucose monitoring variably integrated into each other) that might generate a series of psychological-behavioral reactions related to the integration between technology and body image and the experience of social acceptance of the individual, particularly in the evolution age.
\end{abstract}

Keywords: anxiety; depression; diabulimia; developmental age

\section{The Emotional Aspects Affecting Diabetes in Adult (M.A. Taras)}

\section{Introduction}

Diabetes mellitus and cardiovascular diseases act like two sides of the same coin: diabetes is considered as an equivalent of ischemic cardiovascular disease while patients with ischemic cardiovascular disease often have diabetes or pre-diabetes. The two major forms of diabetes are type 1 insulin-dependent diabetes (T1DM) and type 2 non-insulindependent diabetes (T2DM). Although we are interested in diabetes, the premises are in common with other chronic diseases. All chronic diseases have a negative impact on the quality of life and perceived well-being, the uncertain and unpredictable development of the disease exposes from the outset to a higher incidence of anxiety and mood disorders such as depression, which tends to be more frequent in these subjects than in the general population [1]. In diabetes, depression has an incidence two to three times higher and very often remains under-diagnosed [2]. There is evidence that the prevalence of depression is moderately increased in prediabetic patients and in undiagnosed diabetic patients, and 
markedly increased in the previously diagnosed diabetic patients compared to normal glucose metabolism individuals [2]. On the other hand, depression may increase the risk of developing type 2 diabetes by $60 \%$ [3,4]. It seems that there is a bidirectional association between diabetes and depression, a complex relationship that might share biological mechanisms, whose understanding could provide better treatment and improve the outcomes for these pathologies. In diabetic patients, depression remains under-diagnosed and an important aspect for the diabetic specialist would be the awareness of this quite common co-morbidity. Risk factors such as negative body image, perceived poor state of well-being, difficulty in daily management towards dietary and pharmacological therapy significantly alters the quality of life and when coping skills are lacking distress will results, creating a suffering experience that can generate depressive symptoms and/or in a real depression. These factors show differences in sex/gender and a different impact in the different stages of life. Women are surely more affected than men: in adolescence eating disorders and in adulthood the worst perception of quality of life are among the factors most heartfelt. A multidisciplinary approach of the diabetic patient would help to improve the outcomes of both diseases, decreasing the number of DALYs (disability-adjusted life years) and even mortality.

The inability to control and predict the course and outcomes of chronic disease exposes patients to mood fluctuations which are often difficult to manage in which the periods of relative well-being allow a greater adaptive response. On the contrary, during the exacerbation of symptoms, the quality of life is affected, leading to developing emotional symptoms fed by a course that cannot tend to complete healing but only stabilize the symptoms or eventually slow them down. This for many patients means the loss of control over their own body, to which an experience of frustration is added where their social and family role is perceived as a compromise because family members are heavily involved in the management of the disease. This would increase the sense of impotence that, in many patients, could cause a psychological maladaptive response with activation of defense mechanisms where the disease is scotomized, resulting in poor compliance or even turning into subthreshold psychological disorders, or even psychiatric. Emotional vulnerability shows gender peculiarities and more attention is paid now to these differences than in the past. There is general agreement that women suffer from depression two to three times more than men.

\section{Sex/Gender Definition}

Regarding sex and gender, we must do a clarification: gender is a social construct operating at all ages from the fetus in intrauterine ambient to the elderly, that generally transforms a female into a woman and a male into a man, giving the different roles, relationships and the different access to education and occupation attributed to women and men, irrespective of their genetic make-up at the chromosomal level, whereas sex is the biological/hormonal aspect of male and female derived by the presence of chromosomes $X X$ or $X Y$, since the two concepts are jointed and difficult to dissect we will use the term sex/gender from now on as previously suggested by others [5]. The mechanisms underlying the development of certain diseases in women are studied today more than in the past because for long-time women were "de facto" excluded from clinical trials due to the need to use sometimes complex birth control systems in order to avoid pregnancies with new drugs.

\section{Sex/Gender Differences in Diabetes}

Regarding sex/gender clinical differences in diabetes and even in the prediabetic state, nowadays there is several pieces of evidence, although a lot is still controversial either in the response to drugs and in the pathophysiological evolution and chronic complications of the disease. For more details that elude the purpose of this work, we refer to some fairly recent reviews on the subject [5-7]. 
Despite the delay, now we have data showing different gender behaviors that affect different management, in which metabolic control and age also significantly influence the psychosocial response to the disease [8,9]. These differences have also emerged in communication exchanges, thanks to which behaviors and emotions are expressed. There are different sex/gender inclinations in which women tend to manifest their emotions more openly, have strong relational dispositions and show a greater empathic capacity. Despite their multitasking abilities, they show a greater vulnerability to the emotional sphere, and, compared to men, women more easily require help, which may justify the increased prevalence of disorders. In diabetes, it can be observed that despite sudden glycemic changes that affect both sexes, significantly complicating compliance to drug and life behavior indications, the social role played by women (family duties, work) probably leads to neglect of the disease that then becomes an individual responsibility with the emotions tending to be more negative, despite greater efforts in the management and a better knowledge of pathology, resulting in a life of less social support, while in men the management of diabetes takes place more in the family context. In real life, a Korean study explored the relationship between T2DM and employment status, suggesting a greater negative influence of T2DM in women than in men [10]. The role played by the emotional aspects has been well studied, but it is still a topic of debate. There is no agreement between clinicians whether anxiety and mood disorders in diabetes precede diabetes or are the consequence of it. A positive attitude and acceptance towards the pathology lead to greater perceived well-being and this reverberates positively in the management of diabetes. In fact, the close connection between the endocrine and limbic systems causes some emotional states, including anxiety, which promotes the release of adrenaline and cortisol that hinder the action of insulin and consequently cause hyperglycemia. Psychiatric disorders and diabetes also share a bidirectional association, influencing each other in several ways; compared to control groups, diabetic patients have a worse quality of life, depressive disorders and anxiety disorders [11] and have a double chance of incurring a depressive episode compared to non-diabetic subjects $[12,13]$. Therefore, having diabetes and being a woman can significantly increase the risk of having a major depressive disorder [14]. People with diabetes of both sexes are also more likely to suffer from anxiety disorders than non-diabetic people [15]. A Canadian study examined the association between anxiety symptoms and physical inactivity in T2DM diabetic patients aged 40 to 75 years (over a follow up of ten years). It was found that the symptoms of anxiety are significant clinical comorbidities and men, in this case, may represent a particularly vulnerable subgroup [16]. Compared to the quality of life, in a study on a random cohort of T1DM adult diabetics, adult women with long-standing T1DM showed the lower quality of life, probably related to higher frequency and severity of psychopathological syndromes [17]. Additionally, the age of onset seems to show differences, since T1DM women with childhood-onset have greater distress in general [18].

\section{Eating Disorders}

The vulnerability of diabetic patients to different psychological conditions does not allow them to reach adequate levels of compliance and, among these, eating disorders (ED) have also taken on particular importance, precisely because of the consequences in the management of the disease. The real extent of the association between diabetes and ED is still under-estimated and shows peculiarities with anorexia nervosa, bulimia, and uncontrolled ED. The literature reports that the diagnosis of diabetes can lead to the development of ED in T1DM diabetics while in T2DM it seems to be already antecedent to the diagnosis [19], compared to the general population, ED appears to be more frequent in type 1 diabetics. Regarding anorexia nervosa, there are no significant differences in the prevalence in people with T1DM compared to controls whereas in women, a higher prevalence of bulimia is present [20]. A systematic review carried out on electronic databases and meta-analysis found a higher prevalence of alterations in food behavior in adolescents with T1DM diabetes $(39.3 \%)$ compared to controls $(32.5 \%)$ and this was associated with lower blood sugar 
control [21]. A multicenter study on the comorbidities between T1DM and T2DM and ED showed no differences in ED prevalence rates in both types of diabetes with different features of ED distribution, bulimia being more prevalent in T1DM, while binge eating in T2DM. The results show that neither ED nor omission of insulin therapy is necessarily associated with poor blood sugar control [22]. Our interest in ED is mainly in relation to a particular form of dietary behavior: diabulimia, the term of which comes from the words diabetes and bulimia, consisting in the arbitrary reduction or omission of insulin, the result of which is an abrupt rise in blood sugar, in which there is a massive loss of glucose with urine (glycosuria) with calorie loss which also results in rapid weight loss exposing to the risk of ketoacidosis [23]. It was identified by a group of British physicians in around 2009 who observed that a number of T1DM diabetic patients, predominantly female, did not properly handle the prescribed insulin doses: this can be defined as a subtype of ED [24]. There is no consistent explanation for the origin of the disturbance. As for ED in the general population, this type of disorder shows sex/gender differences: it is more frequent in the female sex and increases with age, with a prevalence that can reach up to $40 \%$ of young adults with T1DM [25]. The chronic nature of the disease has additional risk factors that would favor its development, such as poor self-image, the constant attention to diet and the action of insulin on weight gain, factors that contribute synergistically and condition the course leading to extreme choices such as precisely reducing or omitting insulin to achieve the ideal weight [26]. In one study, the intentional omission affected about $31 \%$ of women of all ages but only 8,8\% reported frequent omissions [27].

An unexplained metabolic imbalance can be considered as a wake-up call to which clinicians should pay more attention as the phenomenon is growing. This disease in diabetes is still very undervalued, partly because the tests available for the diagnosis of the disorder do not take into account that in diabetes, the diet has a fundamental role and excessive attention to the same may be the cause of the exacerbation of the disorder. In addition, in the Diabetes Units often there are no specific professional skills, such as psychologists, that through the use of clinical tests and interviews can bring to light this type of problem, that if not properly investigated could run into false diagnosis. In a study aimed at investigating whether in women with T1DM insulin restriction led to an increase in morbidity and mortality, compared to other psychological distress, in an 11-year follow-up study in 234 women with T1DM, authors found that deceased women reported more significant ED symptoms $(p<0.05)$ and a more frequent insulin restriction $(p<0.05)$ at baseline as compared to survived women [28]. In this regard, we recently conducted a survey in our Diabetic Unit, aimed at assessing the presence of generic disorders of dietary behavior in a diabetic population in intensive insulin treatment consisting of T1DM and T2DM with at least four insulin injections a day, divided by gender and age. We administered the DEPS-R questionnaire anonymously [29] in two ways: in-person while waiting for the visit in the clinic and online via a spreadsheet that can be filled in on the website "www.janasdia.com" accessed on 10 October 2020. The analysis of the data shows no differences between the two routes of administration of the questionnaire and therefore the results were analyzed in their entirety: $n=410$ diabetic patients in intensive insulin therapy with four injections/day (Table 1: T1DM = 314; T2DM =96). The DEPS-R questionnaire is considered positive when the total score is equal to/more than 22 . The score is obtained from the sum of the answers, where never $=0$ while always $=5$. In addition to considering the test in its completeness, were also analyzed the answers to some questions particularly addressed the failure to administer insulin voluntarily, namely questions number 4,9,11, 13 and 16. The female sex showed a significant prevalence on the male sex $(p=0.049)$ in the overall sample in reaching the positive quorum of 22 , this trend was maintained after dividing the subjects in T1DM and T2DM. The positive T2DM subjects did not differ in age and duration of diabetes compared to the negative ones, while in positive T1DM male subjects had a significant $(p=0.018)$ age difference, belonging on average to the most advanced age groups (over 40 years). In addition, by analyzing the scores of the answers to the questions in their entirety, the female sex confirmed both in 
T1DM and in T2DM, a score in its entirety significantly higher, which remained positive in T1DM (0.0447) and T2DM (0.049), see Table 1. By analyzing the scores for the most significant questions related to diabulimia, the female sex presented a score significantly higher than the male $(p=0.0172)$ in T2DM for question 9 "I try to keep my blood sugar high so that I will lose weight" and for question 11 "I feel fat when I take all of my insulin" in T1DM $1(p=0.0004)$, while no significant differences were evident for the other applications. Regarding the more specific question 8, "I make myself vomiting" a total of 17 people with no sex differences responded positively, but with a higher prevalence in T1DM (T1DM: $F=5, M=8$; T2DM: $F=2, M=2$ ). Our research confirms that there are eating disorders below the threshold in a not negligible prevalence in diabetic patients without large differences between type 1 and 2, but with clear sex/gender differences.

Table 1. Results DPRS-R test in T1DM and T2DM divided for sex.

\begin{tabular}{|c|c|c|c|c|}
\hline & \multicolumn{4}{|c|}{ Diabetes } \\
\hline & \multicolumn{2}{|c|}{ T1DM } & \multicolumn{2}{|c|}{ T2DM } \\
\hline & $\mathrm{M}$ & $\mathrm{F}$ & M & $\mathrm{F}$ \\
\hline $\mathrm{N}=410$ & 133 & 181 & 44 & 52 \\
\hline $\begin{array}{l}\text { Age (years) } \\
\text { Mean } \pm \text { SD }\end{array}$ & $28 \pm 6^{*}$ & $27 \pm 7^{*}$ & $58 \pm 9$ & $62 \pm 10$ \\
\hline $\begin{array}{c}\text { DPRS-R } \\
\text { SCORE } \geq 22, \text { n (\%) }\end{array}$ & $8(6 \%)$ & $20(11 \%)$ & $9(21 \%)$ & $19(36 \%)$ \\
\hline$p$ & \multicolumn{2}{|c|}{$p=0.0447$} & \multicolumn{2}{|c|}{$p=0.049$} \\
\hline
\end{tabular}

Data in Table 1 represent the four groups studied: male and female T1DM and male and female T2DM: numbers in each group, as well as mean age \pm SD of the different groups and the number (\%) of positive answers to DPRS-R test with statistical significance, is also given. To determine if the means of the sets of data regarding age were significantly different from each other we used the independent (unpaired) samples $t$-test, while Pearson Chi-squared test were used to test differences in \% positive answers to DPRS-R score. T1DM = type 1 insulindependent diabetes, T2DM = type 2 insulin-independent, but insulin-treated patients, $M=$ male, $F=$ female, $\mathrm{n}=$ number. ${ }^{*} p<0.01 \mathrm{~T} 1 \mathrm{DM}$ vs. T2DM, male vs. female within each group were not significantly different for age. Pearson Chi-square revealed significant differences between males and females within each group of diabetic patients, without differences between the two different kinds of diabetes.

\section{Patient and Care Provider Dyads}

Last but not least important we must remember that compliance to drug treatment and lifestyle changes implies of course patient and care provider collaboration, thus emphasizing the role of patient and care provider dyads. Nevertheless, guidelines do not deeply consider the sex/gender of care providers, forgetting that he/she is a person, and every individual is sexed and gendered. However, the importance of care provider sex/gender is emerging and its influence on health quality has been known for a long time [30,31]. During communication training, these differences should be taken into account, especially to strengthen male communication skills and improve their attitudes [32], since it appears evident that physician gender influences quality of care in patients with type 2 diabetes, with female physicians providing overall better quality of care, especially in prognostic important risk factors management [33]. It was suggested that the influence of sex/gender on adherence appears particularly important, thus programs aimed to address men- and women-specific needs are recommended to increase adherence in both sexes, paying attention also to caregiver-patient dyads [34].

\section{Conclusions First Part}

In this first part, we mainly analyzed the psychological aspects related to the differences in sex/gender in diabetes in adulthood. Particular attention was given to eating disorders that are present as a subsoil condition in diabetic disease with a prevalence not suspected in the past. These disorders may be pre-existing to diabetic disease or they might be the consequence of a number of restrictions mainly food, imposed by the diabetic disease. 
Now we will analyze the paths that can lead to the definition of gender during the various stages of growth, an important chapter to better define the mechanisms in adulthood. A chapter will also address the possible psychological impact that technologies may have in the development of gender differences inherent in the acceptance of the diabetic disease.

\section{The Acquisition of Itself during Evolution (A. Pellegrini)}

\section{The Three Phases Relating to the Acquisition of Gender Identity during Childhood}

As already pointed out, the term gender expresses the social meaning assumed by sexual differences, it represents the constellation of elements and behaviors associated with males and females and therefore expected from them within the community. Gender identity is the result of a process of identity construction that begins in early childhood and continues throughout life, assuming stability only in the post-adolescent era. Speaking of gender identity means referring to the perception that the subject has of himself and it is not comparable to the mere sex of belonging assigned at birth [35]. During childhood, three phases, relating to the acquisition of gender identity, can be identified [36,37]:

- Gender membership: Children from the age of two are able to discriminate whether they are male or female.

- Gender stability: Children from 4 years of age realize that the sex of a person remains unchanged for life.

- Gender perseverance: children aged 6/7 years recognize their gender identity even if not matched with their physical appearance.

Several studies highlight the importance of the quality of the child's first emotional relationships while taking into high consideration the multifactorial aspects that affect the development of the self and gender identity [37,38]. A child's response to chronic disease varies with age. As early as 1930 Anna Freud [39] had highlighted how physical illness could have consequences on the psychological development of the child, especially if it lasted a long time. Hospitalization and prolonged care could interrupt or interfere in the very delicate evolutionary process of the child with different consequences related to the age of onset of the disease, its severity, its duration. In this regard, in fact, it is important to recognize and understand the reciprocal effects between chronic disease and the process of maturation. Given the fact that any chronic disease can interfere, in a transitory or permanent way, with the physiological processes of maturation and development, in the same manner, the opposite can happen, that is physiological transformations, and consequently, psychosocial adaptations can have a positive or negative influence on the natural history of a disease. In a study conducted in a Pediatric Diabetes Center in southern Italy, the psychological problems and self-perception of a sample of 81 children with Type 1 Diabetes Mellitus (T1DM) were assessed. A graphic test was used, the drawing of the human figure according to the "Draw a Person procedure: Screening Procedure for Emotional Disturbances". It was found that children with diabetes drew the smallest human figures, highlighting aspects of the body image different from those of the healthy control group. However, no gender differences emerged. The results support the need to monitor the characteristics of the perception of body image in children with T1DM during their development course, in order to prevent the onset of psychological discomfort.

On the other hand, health facilities today appear and tend to be more organized and responsive to the needs of patients in developmental age with chronic diseases. The management of the chronic disease requires special skills on the part of the doctor who takes care of young patients, the latter should possess, in addition to the specific skills of the actual pathology, knowledge of the psychological and social aspects of the subject and his family. This cognitive need is maintained when the patient is an adolescent. During this phase of growth, the question of identity assumes a central value, being the phase of the redefinition of the self and self-image. The non-negligible role of the body, which is central in the psychic development of the individual, in this period, assumes a 
greater resonance, in a rapid and sudden way the body is transformed, taking on strange, disharmonious appearances that procure new and disturbing sensations in a mind that is in part anchored to infantile functioning. These transformations set up a real emotional storm which the subject must come face to face with and have to integrate into his own psyche. The adolescent experience goes through moments of uncertainty, sadness, fear and this condition can determine the appearance of negative feelings towards oneself and towards one's perception as being responsible for having generated a non-perfect body. Dissatisfaction can evolve in forms of discomfort: self-injurious behaviors and acting out, drastic diets, depression, isolation and so on. This delicate phase can become even more so when you have a chronic disease. The disease affects the body and is a source of physical and mental suffering. It generates experiences and defensive mechanisms, and in some cases, it becomes a constant in everyday life, causing changes in daily habits. The condition of T1DM significantly affects and influences the life habits of the subject and, therefore, everyone, but in particular, the adolescent may show a certain difficulty in emotional adaptation to the disease, reacting in some ways: anger, denial of the disease, sense of injustice, amplification of the negative aspects of the disease, identification with one's own disease, an association of diabetes with all difficult complex and negative experiences, feeling of diversity.

The optimal control of diabetes at this stage of development represents a "problem" for the adolescent himself, for his family and for the diabetes team taking care of him. Gender differences can influence the doctor-patient relationship in the treatment path. It is therefore necessary that the specialist doctor, in addition to being competent in his discipline, knows the bases of the emotional-affective-relational development of the individual so that he can understand the resonances in the therapeutic path. The scientific literature shows that male adolescents are more prone to agitation and impulsiveness than females who show greater criticality in the emotional dimension and body perception. The diabetic adolescent can experience strong emotions as a function of the dilemma experienced within himself, generated by the solicitations coming from the peer group, that sometimes push in the opposite direction to the choices that in reality, he should make as more appropriate for his health. In the diabetic adolescent, this conflict and the natural defiant behavior, expression of the desire for perception and identification of the limit, could have a negative impact on the correct execution of insulin therapy, for example being the cause of delay or non-intake of the same. In girls, on the other hand, the obligatory attention to nutrition could stimulate or amplify issues related to physical appearance and weight control, the effects of which could negatively reflect on the remodeling of insulin therapy or could create the basis for the development of an eating disorder. Sometimes there is a delay in the age of menarche in girls, especially if the onset of diabetes occurred in the first puberty, this could have psychological effects and consequences. At the conclusion of a study [40], whose goal was to investigate age at menarche in young women withT1DM and examine the effect of diabetes management (HbA1c level, number of blood glucose checks, insulin therapy intensity, and insulin dose) on age at menarche, in those diagnosed before menarche (about 300 very young T1DM girls) it emerged that the mean age at menarche is greater than the mean age of the non-diabetic, although the distance in time is reduced as better glycemic control is achieved. Ages at menarche and diagnosis were not associated. For those diagnosed before menarche, age at menarche was delayed 1.3 months with each $1 \%$ increase in mean total $\mathrm{HbA} 1 \mathrm{c}$ level in the 3 years before menarche.

\section{Gender Dysphoria}

Another important issue in adolescence is gender dysphoria (suffering that results from the inconsistency between gender and gender identity). Adolescents with gender dysphoria are described as the most psychologically and socially vulnerable population. It is a condition that is associated with profound psychological suffering and the associated psychopathologies seem to have their onset or strengthen at the same time as pubertal development since at this moment there is a confrontation with a body that changes in an 
unwanted direction. In a very recent publication [41] the authors studied the prevalence of gender dysphoria (GD) in youth given the fact that environmental triggers, such as psychological minority stress experienced by youth with GD, may influence the management of T1DM (10 to 21 years) with important clinical implications. The objective of this study was to determine the prevalence of concurrent diagnosis of T1DM and GD in adolescents evaluated at a university-based children's hospital. Data were collected for 749,284 individual patients during the review period (ten years follow-up). There were 2017 patients diagnosed with T1DM for a prevalence rate of 2.69 per 1000 and 315 patients diagnosed with GD for a prevalence rate of 0.42 per 1000. Concurrent diagnosis of both T1DM and GD was found in eight patients. The prevalence rate for T1DM in the non-GD population is 2.68 (95\% CI 2.57-2.80) per 1000 vs. 24.77 (95\% CI: $12.60-48.10)$ per 1000 in the GD population $(p<0.0001)$. The prevalence of T1DM in the population of adolescents diagnosed with GD is 9.4-fold higher (95\% CI: 4.7-19.1, $p<0.0001$ ) than the prevalence rate of T1DM alone in the overall adolescent patient group. Glycemic control initially improved after the first GD clinic visit over a mean interval of 5 months but was not sustained. There was no improvement in $\mathrm{HbA1c}$ in those that initiated puberty blocker therapy and gender-affirming hormone therapy. Stress reduction due to initiation of gender-affirming hormone therapy could lead to short-term improvement in diabetes control in adolescents with T1DM and GD. Glycemic control in T1DM often worsens during adolescence due to puberty-related insulin resistance and treatment adherence in T1DM often declines during adolescence (decrease in parental oversight and an increase in the prevalence of psychiatric comorbidities). For those adolescents with T1DM and GD who have established a trusting relationship with their diabetes team it could be more comfortable discussing gender identity and may be more likely to seek medical care related to gender identity. Lack of such a relationship with health care providers can impede or delay the diagnosis of GD. In a study [42] conducted at Oslo University Hospital in Norway, on a sample of 105 adolescents with T1DM, (12-20 years) of which 44 males and 61 females, 65.3\% were insulin pump users and $33.7 \%$ on multiple daily insulin injections therapy. Among this population, significant gender differences were observed in disease perception, insulin concern, and social and family coping strategies. The results of the study showed that females had significantly higher negative perceptions of their T1DM than males on all of the Brief Illness Perception Questionnaire (BIPQ) items $(p<0.05)$. Females instead scored significantly higher than males on insulin concern $(p<0.001)$, indicating more negative perceptions/more concerns about insulin. Males and females did not significantly differ in their perceptions of insulin necessity. There were no statistically significant differences in insulin beliefs between patients treated with insulin pumps versus the pen. Patients using an insulin pen had however significantly more negative views on treatment control than patients using pumps, respectively $(p<0.05)$. With regard to the subscales, females scored significantly higher on being social and solving family problems (both $p^{\prime} \mathrm{s}<0.01$ ), indicating more positive coping among females than males for these subscales. There were no statistically significant differences in coping strategies between patients treated with insulin pumps versus a pen. In conclusion, the study highlights how the management of psychological aspects can be a clinically important supplement to the treatment of T1DM and that a tailored therapeutic approach for males and females can be justified.

\section{Psychological Aspect of Technology in Diabetic Patients}

Regarding the possible influence of technology in diabetes, we must consider that the use of the insulin pump and/or sensor for continuous glucose monitoring could generate a series of psychological-behavioral reactions related to the integration between it and the body image and the experience of social acceptance of the individual. The impact that the insulin pump has on body image is also affected by gender differences [43]:

- $\quad$ Adolescent females express this impact more and express their concern regarding the integration of a mechanical device into their own body; their uncertainties are 
expressed in terms of perception of the insulin pump as an external or internal presence in one's body.

- Adolescents males have less concern and less hesitation with respect to social approval in relation to the use of the insulin pump.

Age, male gender, and social deprivation are still associated with a lower rate of insulin pump therapy initiation at least in adults with T1DM and it is well established that an improved clinical outcome is associated with the early initiation of insulin pump therapy in children with type 1 diabetes [44]. The psychological aspect of sex/gender difference must be taken into account in order to optimize pump therapy and the other technological devices such as continuous glucose monitoring in these patients. Since the impact that "technology" has on body image is affected by gender differences, the management of psychological aspects is a clinically important supplement to a tailored therapeutic approach for males and females.

In light of the foregoing, the help and support provided to adolescents in this phase of development and criticality can lead to a positive effect and the success of the treatment process. At the same time, they influence the process of raising awareness of the state of health. The relationship is an integral part of the treatment process and, above all, in the case of chronic illness, it is much more of a powerful tool that facilitates the involvement of the adolescent facilitating and strengthening the latter's ability to draw on inner resources to be able to creatively coexist with his pathology. In the relationship of care and help, one must know how to accept, listen and put the other at ease, managing to keep the right distance and, at the same time, showing empathy. It is necessary to assist and accompany the adolescent in this phase of transition, to recognize and pay attention to his symptoms as alarm bells and to help him towards empowerment.

\section{Key Messages (M.A.Taras)}

At the end of this manuscript we can say that the psychological aspects of chronic diseases, such as diabetes, play an important role in the evolution of the disease and its management, ultimately with repercussions on compliance to drug and lifestyle modifications. These aspects, which vary according to sex/gender and age, as well as the context in which the patient lives, require psychologists trained in chronic diseases who should be part of the diabetologist team.

Author Contributions: Conceptualization, M.A.T. and A.P.; methodology, M.A.T. and A.P.; resources, M.A.T. and A.P.; writing—original draft preparation, M.A.T. and A.P.; writing—review and editing, M.A.T. and A.P. M.A.T. and A.P. contributed equally to the paper been in charge of respective chapters as indicated by the names. All authors have read and agreed to the published version of the manuscript.

Funding: This research received no external funding.

Institutional Review Board Statement: Not applicable.

Informed Consent Statement: Not applicable.

Data Availability Statement: Not applicable.

Acknowledgments: We want to thank all the patients who voluntarily responded to the DEPS-R questionnaire.

Conflicts of Interest: The authors declare no conflict of interest in this paper.

\section{References}

1. Evans, D.L.; Charney, D.S. Mood Disorders and medical illness: A major public health problem. Biol. Psychiatry 2003, 54, 177-180. [CrossRef]

2. Bădescu, S.V.; Tătaru, C.; Kobylinska, L.; Georgescu, E.L.; Zahiu, D.M.; Zăgrean, A.M.; Zăgrean, L. The association between Diabetes mellitus and Depression. J. Med. Life 2016, 9, 120-126.

3. Mezuk, B.; Eaton, W.W.; Albrecht, S.; Golden, S.H. Depression and type 2 diabetes over the lifespan: A meta-analysis. Diabetes Care 2008, 31, 2383-2390. [CrossRef] [PubMed] 
4. $\quad$ Rubin, R.R.; Ma, Y.; Marrero, D.G.; Peyrot, M.; Barrett-Connor, E.L.; Kahn, S.E.; Haffner, S.M.; Price, D.W.; Knowler, W.C. Elevated depression symptoms, antidepressant medicine use, and risk of developing diabetes during the diabetes prevention program. Diabetes Care 2008, 31, 420-426. [CrossRef]

5. Franconi, F.; Campesi, I.; Occhioni, S.; Tonolo, G. Sex-gender differences in diabetes vascular complications and treatment. Endocr. Metab. Immune Disord. Drug Targets 2012, 12, 179-196. [CrossRef]

6. Seghieri, G.; Policardo, L.; Anichini, R.; Franconi, F.; Campesi, I.; Cherchi, S.; Tonolo, G. The Effect of Sex and Gender on Diabetic Complications. Curr. Diabetes Rev. 2017, 13, 148-160. [CrossRef] [PubMed]

7. Campesi, I.; Occhioni, S.; Tonolo, G.; Cherchi, S.; Basili, S.; Carru, C.; Zinellu, A.; Franconi, F. Ageing/Menopausal status in healthy women and aging healthy men differently affect cardiometabolic parameters. Int. J. Med. Sci. 2016, 13, 124-132. [CrossRef]

8. Siddiqui, M.A.; Khan, M.F.; Carline, T.E. Gender Differences in Living with Diabetes Mellitus. Mat. Soc. Med. 2013, 25, 140-142. [CrossRef]

9. Kim, J.H.; Lee, W.Y.; Lee, S.S.; Kim, Y.T.; Hong, Y.P. Gender Differences in the Relationship between Type 2 Diabetes Mellitus and Employment: Evidence from the Korea Health Panel Study. Int. J. Environ. Ris. Public Health 2020, 17, 7040. [CrossRef]

10. Balhara, Y.P. Diabetes and psychiatric disorders. Indian J Endocrinol. Metab. 2011, 15, 274-283. [CrossRef]

11. Lustman, P.J.; Penckofer, S.M.; Clouse, R.E. Recent advances in understanding depression in adults with diabetes. Curr. Psychiatry Per. 2008, 10, 495-502. [CrossRef] [PubMed]

12. Eaton, W.W. Epidemiologic evidence on the comorbidity of depression and diabetes. J. Psychosom. Res. 2002, 53, 903-906. [CrossRef]

13. Anderson, R.J.; Freedland, K.E.; Clouse, R.E.; Lustman, P.J. The prevalence of comorbid depression in adults with diabetes: A meta-analysis. Diabetes Care 2001, 24, 1069-1078. [CrossRef]

14. Deischinger, C.; Dervic, E.; Leutner, M.; Kosi-Trebotic, L.; Klimek, P.; Kautzky, A.; Kautzky-Willer, A. Diabetes mellitus is associated with a higher risk for major depressive disorder in women than in men. BMJ Open Diabetes Res. Care 2020, 8, e001430. [CrossRef] [PubMed]

15. Vaghela, K.J. Anxiety among Diabetic and non Diabetic Male \& Female. Int. J. Indian Psychol. 2016, 3, 76.

16. Lipscombe, C.; Smith, K.J.; Gariépy, G.; Schmitz, N. Gender differences in the relationship between anxiety symptoms and physical inactivity in a community-based sample of adults with type 2 diabetes. Can. J. Diabetes 2014, 38, 444-451. [CrossRef]

17. Castellano-Guerrero, A.M.; Guerrero, R.; Ruiz-Aranda, D.; Perea, S.; Pumar, A.; Relimpio, F.; Mangas, M.A.; Losada, F.; MartínezBrocca, M.A. Gender differences in quality of life in adults with long-standing type 1 diabetes mellitus. Diabetol. Metab. Syndr. 2020, 12, 64. [CrossRef]

18. Lašaitė, L.; Ostrauskas, R.; Žalinkevičius, R.; Jurgevičienè, N.; Radzevičienè, L. Diabetes distress in adult type 1 diabetes mellitus men and women with disease onset in childhood and in adulthood. J. Diabetes Complicat. 2016, 30, 133-137. [CrossRef] [PubMed]

19. Gagnon, C.; Aimé, A.; Bélanger, C. Predictors of Comorbid Eating Disorders and Diabetes in People with Type 1 and Type 2 Diabetes. Can. J. Diabetes 2017, 41, 52-57. [CrossRef]

20. Mannucci, E.; Rotella, F.; Ricca, V.; Moretti, S.; Placidi, G.F.; Rotella, C.M. Eating disorders in patients with type 1 diabetes: A meta-analysis. J. Endocrinol. Investig. 2005, 28, 417-419. [CrossRef]

21. Young, V.; Eiser, C.; Johnson, B.; Brierley, S.; Epton, T.; Elliott, J.; Heller, S. Eating problems in adolescents with Type1 diabetes: A systematic review with meta-analysis. Diabet. Med. A J. Br. Diabet. Assoc. 2013, 30, 189-198. [CrossRef] [PubMed]

22. Herpertz, S.; Albus, C.; Wagener, R.; Kocnar, M.; Wagner, R.; Henning, A.; Migliore, F.; Foerster, H.; Schulze, S.B.; Thomas, W.; et al. Comorbidity of diabetes and eating disorders. Does diabetes control reflect disturbed eating behavior? Diabetes Care 1998, 21, 1110-1116. [CrossRef] [PubMed]

23. Tonolo, G.; Taras, M.A. Sex-Gender Difference in Diabetes: A Physiological and Psychological Point of View. Women Health Complicat. 2021, 1, 1-6.

24. Diabulimia. Available online: https:/ /it.wikipedia.org/wiki/Diabulimia (accessed on 16 June 2021).

25. Pinhas-Hamiel, O.; Hamiel, U.; Levy-Shraga, Y. Eating disorders in adolescents with type 1 diabetes: Challenges in diagnosis and treatment. World J. Diabetes 2015, 6, 517-526. [CrossRef]

26. Baginsky, P. A patient's perspective A Battle to Overcome "Diabulimia" Commentary. Am. Fam. Physician 2009, 79, $263-268$.

27. Polonsky, W.H.; Anderson, B.J.; Lohrer, P.A.; Aponte, J.E.; Jacobson, A.M.; Cole, C.F. Insulin omission in women with IDDMI. Diabetes Care 1994, 17, 1178-1185. [CrossRef] [PubMed]

28. Goebel-Fabbri, A.E.; Fikkan, J.; Franko, D.L.; Pearson, K.; Anderson, B.J.; Weinger, K. Insulin restriction and associated morbidity and mortality in women with type 1 diabetes. Diabetes Care 2008, 31, 415-419. [CrossRef]

29. Markowitz, J.T.; Butler, D.A.; Volkening, L.K.; Antisdei, J.E.; Anderson, B.J.; Laffei, L.M.B. Brief screening tool for disordered eating in diabetes. Diabetes Care 2010, 33, 495-500. [CrossRef] [PubMed]

30. Domenighetti, G.; Luraschi, P.; Marazzi, A. Hysterectomy and sex of the gynecologist. NEJM 1985, 313, $148-153$.

31. Lurie, N.; Slater, J.; McGovern, P.; Ekstrum, J.; Quam, L.; Margolis, K. Preventive Care for women: Does the sex of the physician matter? NEJM 1993, 329, 478-482. [CrossRef]

32. Seitz, T.; Billeth, S.; Pastner, B.; Preusche, I.; Seidman, C. Significance of gender in the attitude towards doctor-patient communication in medical students and physicians. Wien. Klin. Wochenschr. 2016, 128, 663-668. 
33. Berthold, H.K.; Gouni-Berthold, I.; Bestehorn, K.P.; Böhm, M.; Krone, W. Physician gender is associated with the quality of type 2 diabetes care. J. Intern. Med. 2008, 264, 340-350. [CrossRef] [PubMed]

34. Franconi, F.; Campesi, I. Sex and gender influences on pharmacological esponse: An overview. Expert Rev. Clin. Pharmacol. 2014, 1-17.

35. Kjellberg, G. Acquiring a sexual identity. Rev. Med. Suisse 2013, 9, 606-609. [PubMed]

36. Meyer, J.K. The theory of gender identity disorders. J. Am. Psychoanal. Assoc. 1982, 30, 381-418. [CrossRef]

37. Malik, F.; Marwaha, R. Developmental Stages of Social Emotional Development. In Children; StatPearls Publishing: Treasure Island, FL, USA, 2021.

38. Hornor, G. Attachment Disorders. J. Pediatr. Health Care 2019, 33, 612-622. [CrossRef] [PubMed]

39. Freud, A. Normality and Pathology in Childhood: Assessments of Development; Routledge: London, UK, 1965.

40. Danielson, K.; Palta, M.; Allen, C.; D'Alessio, D.J. The Association of Increased Total Glycosylated Hemoglobin Levels with Delayed Age at Menarche in Young Women with T1DM. J. Clin. Endocrinol. Metab. 2005, 90, 6466-6471. [CrossRef]

41. Logel, S.N.; Bekx, M.T.; Rehm, J.L. Potential association between T1DMmellitus and gender dysphoria. Pediatric Diabetes 2020, 21, 266-270. [CrossRef]

42. Wisting, L.; Bang, L.; Skrivarhaug, T.; Dahl-Jørgensen, K.; Rø, Ø. Psychological barriers to optimal insulin therapy: More concerns in adolescent females than males. BMJ Open Diabetes Res. Care. 2016, 4, e000203. [CrossRef]

43. Meunier, L.; Aguadé, A.S.; Videau, Y.; Verboux, D.; Fagot-Campagna, A.; Gastaldi-Menager, C.; Amadou, C. Age, Male Gender, and Social Deprivation Are Associated with a Lower Rate of Insulin Pump Therapy Initiation in Adults with Type 1 Diabetes: A Population-Based Study. Diabetes Technol. Ther. 2021, 23, 8-19. [CrossRef] [PubMed]

44. Kamrath, C.; Tittel, S.R.; Kapellen, T.M.; von dem Berge, T.; Heidtmann, B.; Nagl, K.; Menzel, U.; Pötzsch, S.; Konrad, K.; WHoll, R. Early versus delayed insulin pump therapy in children with newly diagnosed type 1 diabetes: Results from the multicentre, prospective diabetes follow-up DPV registry. Lancet Child Adolesc. Health 2021, 5, 17-25. [CrossRef] 